\title{
Reflecting on the use of photo elicitation with primary school children
}

\section{Abstract:}

Aim:

To reflect on the use of photo elicitation as a data collection method when conducting research with primary school age children (9-11 years)

\section{Background:}

There is now recognition that children feel an affinity with the visual medium; as a result, visual methods can be very appropriate when conducting research with children. Photo elicitation is a method that has previously been used, but there has been little discussion of its use with primary school children within a health context. This paper considers the key issues that warrant consideration by researchers.

\section{Data sources:}

This paper draws on a research study, conducted by the author that drew on an ethnographic approach and a photo elicitation method, to identify the assets underpinning children's wellbeing.

\section{Review methods:}

This paper provides a reflective discussion to highlight issues relating to the use of photo elicitation as a data collection method for primary school children. 


\section{Discussion:}

Photo elicitation is not without its challenges; it raises added ethical considerations - it can be more time-consuming and expensive. However, children value the opportunity of being involved in research and having their opinions sought - photo elicitation provides a method of data collection that is appropriate for children's developmental and cognitive maturational stages.

\section{Conclusion:}

Photo elicitation can be a very positive experience for children that is not only fun and engaging, but one that is also empowering and valuing of their contributions.

\section{Implications of future research/practice:}

The planning of research that uses photo elicitation requires careful and in-depth consideration to ensure that the study is appropriately supported. Despite this, it can offer a unique insight into children's lives that allow health professionals to deepen their understanding of children's experiences.

Key Words: Children; photo elicitation; data collection; research 


\section{Introduction}

Research has, for many years, demonstrated a strong interest in the lives of children across the age ranges; however, studies have primarily focussed on the adult perspective, rather than valuing the voice of the child (Prout and James, 1997). More recently, a growing body of research recognises children's ability to make a valuable contribution to studies, particularly those that directly impact on them (for example, Christensen, 2002; Goodenough et al, 2003; Nic Gabhainn and Sixsmith, 2006; Coad and Coad, 2008; Fattore et al, 2009; Gibson et al, 2010). Whilst there are some challenges in relation to the involvement of children (Whiting, 2009), it is essential that every effort is made to facilitate their participation so that their "authentic voices" can be heard (Dyson and Meagher, 2001, p67). There is recognition that visual methods can be very appropriate when conducting research with children, especially as children feel an affinity with this medium (Thomson, 2008). It is also acknowledged that visual research with children can facilitate the communication of their thoughts and emotions (Leitch and Mitchell, 2007) and that it frequently provides an additional and valuable perspective to methods that purely focus on either the spoken or written word (for example, Burke and Grosvenor, 2004; Kaplan and Howes, 2004; Veale, 2005). Perhaps, most importantly, visual methods provide satisfaction for children and give the opportunity of "getting something" out of the experience (Thomson, 2008, p11).

Whilst there a range of visual approaches that can inform data collection (for example, drawings, videos, maps), photography is attracting an increased interest. Several research studies have now been undertaken that have combined the use of photography by participants (Oliffe and Bottorff, 2007; Erdner et al, 2009; Roberts, 2009; Graham and Kilpatrick, 2010); however, there has been less discussion of the 
value of photo elicitation with younger participants - this paper reflects on its use with primary school-aged children aged between 9-11 years.

\section{Using photo elicitation}

There is a recognised need to use research methods that are appropriate and relevant to children's skills (Punch, 2002) particularly as they may have limited vocabulary and a shorter attention span (Boyden and Ennew, 1997). James et al (1998) comment that it is the researcher's responsibility to ensure that they engage with children whilst Hill (1997, p180) states that there is a need to:

"maximise children's ability to express themselves at the point of datagathering; enhancing their willingness to communicate the richness of findings."

However, it is also essential to acknowledge that children are "competent problem solvers and learners" (Richards, 2009, p4). Careful thought is therefore needed to ensure that the chosen research methods are developmentally appropriate, stimulating and also facilitate the achievement of the study's overall aim.

The use of photography in research with children is not new; Graham and Kilpatrick, (2010) discuss an ethnographic study undertaken with children in primary school years 5 and 6, using a photo elicitation approach; they comment that:

"The photographs taken individually created a platform for children to share their stories" [Graham and Kilpatrick, 2010, p96] 
The technique of "inserting a photograph into a research interview" (Harper, 2002, p13) is termed 'photo elicitation'; this was a phrase originally coined by John Collier (1957), a researcher and photographer. More recently, Hurworth (2003) has highlighted four different approaches to photo elicitation (Table 1).

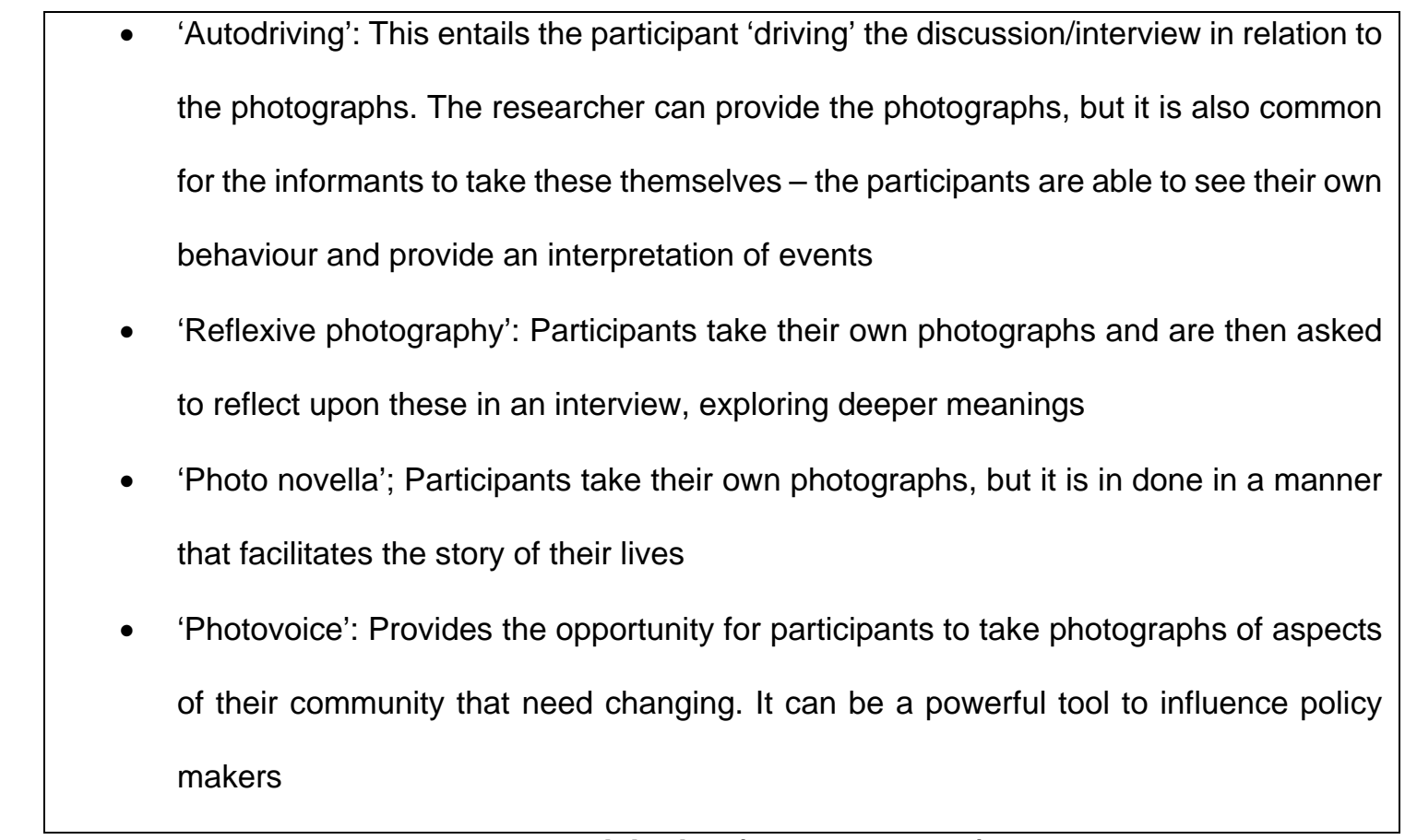

Table 1: Four approaches to photo elicitation (Hurworth, 2003)

Whilst it is possible to use any of the four approaches, highlighted in Table 1, with children, reflexive photography is commonly used as this not only facilitates further insight into children's lives, but is empowering and valuing of their contribution.

\section{Research Method}


A research study (Whiting et al, 2013) was undertaken that drew on an ethnographic approach and a photo elicitation method. Two primary schools in the south-east of England were used to recruit twenty year 5 children (aged 9-11 years). The participants, ten boys and ten girls, were given disposable cameras and asked to take photographs of the activities that they enjoyed. The children's photographs were integral to subsequent individual semi-structured interviews that sought to gain an insight into children's lives and identify the assets underpinning their wellbeing. Ethical approval for the study was granted by University of Hertfordshire Research Ethics Committee for Nursing, Midwifery, Social Work, Criminal Justice and Counselling. Table 2 identifies how photography was used in this study:

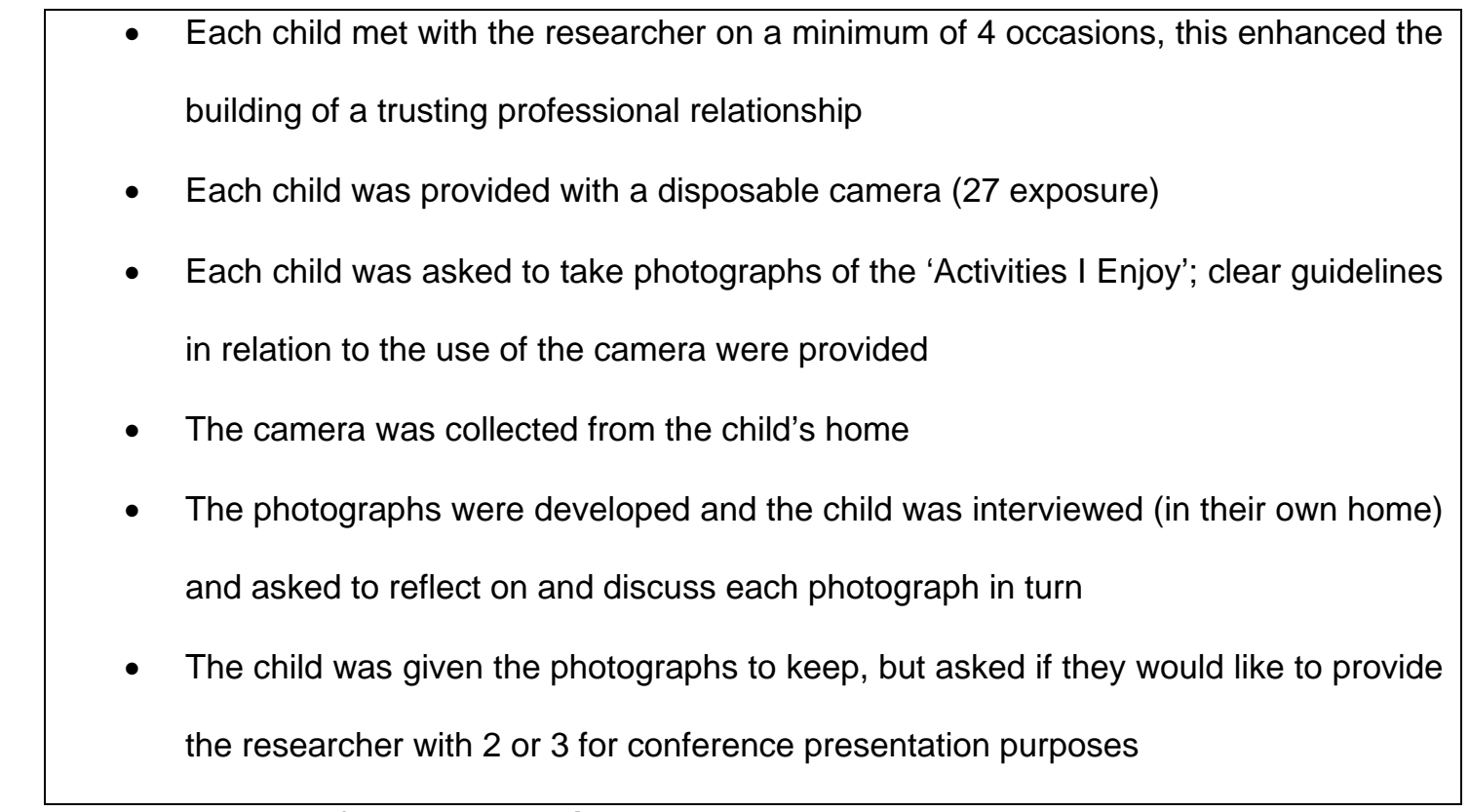

Table 2: The use of photography in the proposed study

As the research was concerned with children's perception of their overall wellbeing, it was essential that the children were able to take the photographs themselves and choose the subject matter as well as the number that they wished to take. All of the children remained in the study until its conclusion and over 400 photographs were 
taken. The length of time that the children had the camera was negotiated and varied between 3-9 weeks (some children wanted to take the camera on holiday so needed it for a longer period).

A number of authors have highlighted the advantages of drawing on photographic methods; Table 3 provides a summary of these.

- It is fun and engaging (Close, 2007), quick and enjoyable (Cook and Hess, 2007)

- A visual prompt for later discussion (Cook and Hess, 2007)

- A tool that enables children to identify what they feel is important (Cook and Hess, 2007)

- Empowering; photography allows the participant to be in control and to make decisions; other techniques, such as drawing may be further influenced by skill and the pictures drawn by peers (Punch, 2002)

- Helpful when presenting and reporting the study (Coad, 2008)

- Children tend to have a strong interest in pictorial representations, including photographs (Coad, 2007)

- Photographs have the ability to provide a clear image from the participant's perspective, this can then be further explored (Morrow, 2001)

Table 3: The potential benefits of photography

However, despite the many strengths of photography, there are challenges. Firstly, it is important to give children clear guidelines in relation to the focus of the research and what they are being asked to take photographs of; in addition, information about the use of the camera is crucial (some of the children in this study had never had a disposable camera before and struggled with the use of the 'flash' component). Rather than disposable technology, digital cameras, iPads or mobile telephones can be used; whilst these may be more user friendly, especially for adolescent participants, there 
are not only cost implications, but there is a danger that photographs can be more readily shared with others outside of the study and there is a potential for a breach of confidentiality. The cost of disposable cameras is relatively small and the children were delighted to receive the ones I gave them.

It is important to remember that photography can be influenced by the seasons (Punch, 2002), therefore, depending on the focus of the research, there could be a subsequent impact on data collection - as a result, I conducted the study over one full calendar year.

\section{Conducting interviews with children}

A key aspect of photo elicitation is the conducting of the interviews; the time and place of these were negotiated with the parent(s) and child - all were held within the home environment. The children were given their photographs and were able to look at them for a while before the interview commenced; the children were excited to see their pictures and it also this provided them with the opportunity to familiarise themselves with the content. In many instances children not only feel more comfortable in their own homes, but it is also often more convenient when family lives are busy. However, it is acknowledged that this environment means that data collection can be more timeconsuming (Scott, 2000) and that it can raise additional concerns. Firstly, Mayall (2000) suggests that the researcher needs to identify their social position within the home - this can be addressed by visiting the child's home on more than one occasion so that a rapport is built with the whole family; this strategy not only facilitates the photo elicitation method, but also allows parents to gain confidence in the researcher. 
Secondly, for safeguarding and child protection reasons, it may not be appropriate to ask to conduct the interview in a private room as this could place the researcher in a difficult position (Barker and Weller, 2003); as a result, parents or family members may be present and this has the potential to influence a child's responses (Scott, 2000). In busy homes, space is often at a premium; therefore, it is usual that other family members are in close proximity during the interviews. Unsurprisingly, parents had a natural curiosity about the study I was conducting and its various stages - being in the home environment allowed me to keep them informed and this in turn meant that I became trusted to be with their children. In addition, the first person that the children wanted to show their photographs to was their parent(s) - it was therefore lovely that they were able to do so. In summary, there are advantages and challenges to conducting children's interviews within the home environment, therefore, the researcher needs to reflect on the options and select the approach that is most conducive to their study.

Interviewing children can be very different to conducting interviews with adults. It is not unusual for adult participants to find an interview cathartic and it might be an opportunity to share significant life experiences - this may mean that interviews are lengthy. However, children between the ages of 9-11 years are still developing cognitively; their language skills are being refined and not all children are able to talk in longer and more complex sentences; this frequently results in brief responses being given by the children to the questions posed. Secondly, the attention span of children varies and can be limited; it is not surprising therefore, that the participants in the research I undertook sometimes wanted to change the direction or focus of their discussion quite abruptly. These factors mean that the overall interview tends to be 
short and concise; I found that interviews lasted for between 22-54 minutes; however, the photographs were crucial in terms of prompting the conversation and providing a clear focus for the interviews. These children were excited to recall their activities and to tell me about their lives - without the photographs, conversation may well have been more difficult to stimulate and maintain.

\section{Data analysis}

There has been discussion within the existing body of literature about the analysis of photographic data and the form that this should take. Mandleco (2013) suggests that each photograph is initially labelled in relation to the participant's details and that the photographs are then collated into separate categories, depending upon their visual content. The availability of the interview transcripts allows the photographs to then be viewed within their context and facilitates the emergence of categories and subcategories. Categorisation, first highlighted by Collier (1979) can be a valuable approach, but Close (2007) argues that this does not allow children to remain empowered. Coad (2012) conducted a photography project in which young people were involved as co-researchers, they then also participated in the analysis and coding of the photographs - involvement of this nature is what researchers should be aspiring to achieve, but unfortunately it is still not always feasible. Each researcher needs to consider the purpose of the photographs and decide on the most appropriate mode of analysis. In my study, the photographs themselves were not subjected to individual analysis; instead the photographs enabled the children to reflect on, explore and illustrate aspects of their lives - the children were eager to share their experiences and the photographs prompted their memory of everyday activities. The interviews 
were transcribed and a constant comparative analysis approach used to facilitate the emergence of the assets underpinning the children's wellbeing.

\section{Ethical considerations}

Whilst several studies, whose participants have been children, have successfully utilised photography (for example, Darbyshire et al, 2005; Epstein et al, 2006; Close, 2007; Cook and Hess, 2007), it is acknowledged that "using photographs as a research tool is not easy" (Donaldson, 2001, page 178). One of the chief concerns that has been expressed is the potential ethical implications - this has limited its use in some areas of health research (Banks, 2001; Riley and Manias, 2004; Graham and Kilpatrick, 2010).

Gaining the informed consent of participants for any research study is, of course, absolutely essential. If children and photography are involved, the situation is complicated slightly further; however, there is no reason why competent children under the age of sixteen years should not consent for themselves (Fargas-Malet et al, 2010); Alderson and Morrow (2011) state that the child is competent if they have enough knowledge and understanding to be able to make an informed decision; some studies (for example, Munford and Sanders, 2004) have gone further by seeking primary consent from the child rather than their parent/guardian. If children are judged to be competent to make their own decision about their involvement, it is certainly appropriate for them to give their consent; however, seeking parental consent as well may be a requirement of ethical approval and may also make the researcher feel more 'comfortable' - for my study, I devised a joint consent sheet. 
The use of photo elicitation raises additional confidentiality concerns and this is already an aspect of research with children that has not always been fully respected (Alderson and Morrow, 2011). To assist with the protection of confidentiality, photographs should only be shared with others outside of the research team if the child and parent(s) have given permission and if the child's features are not identifiable.

If children are given a disposable camera, and the subsequent photographs to keep, this means that they are no different to other personal photographs that they may take - from an ethics approval perspective, this can be advantageous. It is useful to seek ethical approval to ask children if they are willing to give the researcher any of their photographs as these can then be used for conference presentation purposes; building a rapport with the children means that they should have the confidence to say 'no' if they do not wish to part with any; in my experience, children are generally very happy to give photographs to the researcher, especially as children frequently take more than one picture of objects/people that are important to them. In my conference presentations, I have only included photographs of inanimate objects or when a child could not possibly be recognised; whilst pixilation is an option, this can detract from the photograph and there cannot always be absolute assurance that the child would not be identifiable.

Finally, the undertaking of studies frequently prompts researchers to consider whether small gifts should be given to participants as a token of respect and thanks. Whilst gift giving can be ethically contentious (Fargas-Malet et al, 2010), respecting and valuing 
children's contribution and time is important. Therefore, I received ethical approval to give each child a small photograph album and frame in which to store their pictures.

\section{Conclusion}

The value of a photo elicitation approach in terms of gaining insight into children's experiences should not be underestimated. Whilst this form of data collection is undoubtedly more time consuming than some alternatives, it provides the researcher with an opportunity to build a rapport with children and to learn about what is really important to them. The photographs themselves provide additional illustration and context to the children's stories, and as a consequence, this deeper understanding aids the data analysis process. Most importantly, photo elicitation can mean that involvement in a study is a positive experience for the participants:

"I think that it is important that children's views are listened to so if I was asked to take part in another project I think that I would take part especially as I enjoyed doing it. I really enjoyed being part of this project." [Ryan, aged 10 years].

Thank you to the Association of British Paediatric Nurses [ABPN] for awarding a small research grant, this funded the cost of the disposable cameras.

\section{References}

Alderson P, Morrow V (2011) The ethics of research with children and young people. A practical handbook. Sage Publications, London. 
Banks M (2001) Visual methods in social research. Sage Publications, London.

Barker J, Weller S (2003) "Is it fun?" Developing child centred research methods. International Journal of Sociology and Social Policy. 23, 1/2, 33-58.

Boyden J Ennew J (1997)(Eds) Children in focus: A manual for experiential learning in participatory research with children. Rädda Barnen, Stockholm.

Burke C, Grosvenor I (2004) The school l'd like. Routledge Falmer, London.

Christensen P H (2002) Why more 'quality time' is not on the top of children's lists: The qualities of time' for children. Children \& Society. 16, 2, 77-88.

Coad J (2007) Using art-based techniques in engaging children and young people in health care consultations and/or research. Journal of Research in Nursing. 12, 5, 487-497.

Coad J (2008) Personal communication; May 2008.

Coad J, Coad N (2008) Children and young people's preference of thematic design and colour for their hospital environment. Journal of Child Health Care. $12,1,33-48$.

Coad J (2012) Involving young people as co-researchers in a photography project. Nurse Researcher. 19, 2, 11-16. 
Collier J (1957) Photography in anthropology: a report on two experiments. American Anthropologist. 59, 5, 843-859.

Collier J (1979) Evaluating visual data. In Wagner J (Ed) Images of information. Sage, California.

Cook T, Hess E (2007) What the camera sees and from whose perspective: Fun methodologies for engaging children in enlightening adults. Childhood. 14, 1, 2945.

Close H (2007) The use of photography as a qualitative research tool. Nurse Researcher. 25, 1, 27-36.

Darbyshire, P, MacDougall C, Schiller W (2005) Multiple methods in qualitative research. Qualitative Research. 4, 4, 417-436.

Donaldson P J (2001) Using photographs to strengthen family planning research. Family Planning Perspectives. 33, 4, 176-179.

Dyson A, Meagher N (2001) Reflections on the case studies: Towards a rationale for participation? In Clark J, Dyson A, Meagher N, Robson E et al (Eds) Young people as researchers. Possibilities, problems and politics. National Youth Agency, Leicester. 
Epstein I, Stevens B, McKeever P, Barychel S (2006) Photo elicitation interview (PEI): using photos to elicit children's perspectives. International Journal of Qualitative Methods. 5, 3, 1-9.

Erdner A, Andersson L, Magnusson A, Lutzen K (2009) Varying views of life among people with long-term mental illness. Journal of Psychiatric \& Mental Health Nursing. 16, 1, 54-60.

Fargas-Malet M, McSherry D, Larkin E, Robinson C (2010) Research with children: Methodological issues and innovative techniques. Journal of Early Childhood Research. 8, 2 175-192.

Fattore T, Mason J, Watson E (2009) When children are asked about their wellbeing: Towards a framework for guiding policy. Child Indicators Research. 2,1, $57-77$.

Gibson F, Aldiss S, Horstman M, Kumpunen S et al (2010) Children and young people's experiences of cancer care: A qualitative research study using participatory methods. International Journal of Nursing Studies. 47, 11, 13971407.

Goodenough T, Williamson E, Kent J, Ashcroft R (2003) 'What did you think about that?' Researching children's perceptions of participation in a longitudinal genetic epidemiological study. Children \& Society. 17, 2, 113-125. 
Graham A, Kilpatrick R (2010) Understanding children's educational experiences through image-based research (pages 89-106). In Scott Jones J, Watt S (Eds) Ethnography in social science practice. Routledge, London.

Harper D (2002) Talking about pictures: a case for photo elicitation. Visual Studies. 17, 1, 13-26.

Hurworth R (2003) Photo-interviewing for research. Social Research. Update Spring. 40, 1, 1-4.

Hill M (1997) Participatory research with children. Research review. Child and Family Social Work. 2, 3, 171-183.

James A, Jenks C, Prout A (1998) Theorizing childhood. Polity Press, Cambridge.

Kaplan I, Howes A (2004) 'Seeing with different eyes': exploring the value of participative research using images in schools. Cambridge Journal of Education. $34,2,143-155$.

Leitch R, Mitchell S (2007) Caged birds and cloning machines: how student imagery 'speaks' to us about cultures of schooling. Improving Schools. 10, 1, 5371. 
Mandleco B (2013) Research with children as participants: Photo elicitation. Journal for Specialists in Pediatric Nursing. 18, 1, 78-82.

Mayall B (1994) Introduction. In Mayall B (Ed). Children's childhoods observed and experienced. Falmer Press, London.

Morrow V (2001) Using qualitative data to elicit young people's accounts of community and neighbourhood: some ideas for community health initiatives. Health Education Research: Theory and Practice. 16, 3, 255-268.

Munford R, Sanders J (2004) Recruiting diverse groups of young people to research: Agency and empowerment in the consent process. Qualitative Social Work 3(4) 469-482

Nic Gabhainn S, Sixsmith J (2006) Children photographing well-being: Facilitating participation in research. Children \& Society. 20, 4, 249-259.

Oliffe JL, Bottorff JL (2007) Further than the eye can see? Photo elicitation and research with men Qualitative Health Research, 17, 6, 850-858.

Prout A, James A (1997) A new paradigm for the sociology of childhood? Provenance and problems. In James A, Prout A (Eds) Constructing and reconstructing childhood. Contemporary issues in the sociological study of childhood. $2^{\text {nd }}$ Ed. Falmer Press, London. 
Punch S (2002) Research with children: The same or different from research with adults? Childhood, 9, 3, 321-341.

Richards RD (2009) Young visual ethnographers: Children's use of digital photography to record, share and extend their art experiences. International Art in Early Childhood Research Journal. 1, 1, 1-16.

Riley RG, Manias, E (2004) The uses of photography in clinical nursing practice and research: a literature review. Journal of Advanced Nursing. 48, 4, 397-405.

Roberts T (2009) Understanding ethnography. British Journal of Midwifery. 17, $5,291-294$.

Scott J (2000) Children as respondents. The challenge for quantitative methods. In Christensen P, James A (Eds) Research with children. Perspectives and Practices. Routledge Falmer, London.

Thomson P (2008) Doing visual research with children and young people. Routledge, London.

Veale A (2005) Creative methodologies in participatory research with children. In Greene S, Hogan D (Eds) Researching children's experiences: approaches and methods. Sage Publications, London.

Whiting L (2009) Involving children in research. Paediatric Nursing. 21, 5, 3236. 
Whiting L, Kendall S, Wills W (2013): Rethinking children's public health: the development of an assets model, Critical Public Health. 23, 2, 146-159. 